УДК 58.01/07

\title{
АДАПТАЦИЯ РАСТЕНИЙ SYRINGA VULGARIS L. COPTA ПРИМРОУЗ, ПОЛУЧЕННЫХ МЕТОДОМ IN VITRО С ИСПОЛЬЗОВАНИЕМ UTAMMOB PSEUDOMONAS MIGULA
}

Тохтарь Людмила Анатольевна к.б.н., зав. лабораторией биотехнологии растений

Третьяков Михаил Юрьевич к.б.н., зав. лабораторией генетики и селекции растений Ткаченко Наталья Николаевна младший научный сотрудник лаборатории биотехнологии растений

Жиляева Наталья Васильевна инженер лаборатории биотехнологии растений НОЦ «Ботанический сад НИУ «БелГУ»

Аннотация: в статье приводятся данные по влиянию некоторых штаммов Pseudomonas Migula на адаптацию растений, полученных методом in vitro на примере Syringa vulgaris L. сорта Примроуз. Выявлено положительное влияние после обработки субстрата штаммом Pseudomonas protegens $\mathrm{P} 4-2$ в разведении 1:5 приводящее к увеличению длину корней и высоты растений. Обработка субстратов суспензиями штамма Pseudomonas putida P82 в разведении 1:10 способствовала интенсификации процессов корнеобразования.

Ключевые слова: адаптация, in vitro, Syringa vulgaris L., штаммы Pseudomonas

\author{
ADAPTATION OF SYRINGA VULGARIS L. PRIMROSE PLANTS \\ OBTAINED BY IN VITRO METHOD USING PSEUDOMONAS \\ MIGULA STRAINS
}


Tokhtar Lyudmila Anatolyevna

Ph.D., Head. laboratory of plant biotechnology

Tretyakov Mikhail Yurievich

Ph.D., Head. laboratory of genetics and plant breeding

Tkachenko Natalia Nikolaevna junior researcher plant biotechnology laboratories

Zhilyaeva Natalia Vasilievna

plant biotechnology laboratory engineer

SEC "Botanical Garden of the National Research University" BelSU

\begin{abstract}
The article provides data on the influence of some Pseudomonas Migula strains on the adaptation of plants obtained by the in vitro method using the example of Syringa vulgaris L. Primrose cultivar. A positive effect after the substrate treatment with the Pseudomonas protegens P4-2 strain at a dilution of 1: 5, leading to an increase in the length of the roots and the height of plants, was revealed. Treatment of substrates with suspensions of the Pseudomonas putida P82 strain at a dilution of 1:10 promoted the intensification of root formation processes.
\end{abstract}

Key words: adaptation, in vitro, Syringa vulgaris L., Pseudomonas strains/

Адаптация растений к условиям внешней среды является ключевым этапом получения качественного посадочного материала в технологии клонального микроразмножения растений. Перевод укорененных in vitro растений в нестерильные условия приводит к повышенному стрессу, который сопровождается их низкой приживаемостью и нередко гибелью [1]. Как известно растения, могут образовывать ассоциации с различными полезными для них ризосферными бактериями-эпифитами и бактериями-эндофитами для которых взаимодействие с растением не является видо- или штаммоспецифичным [2-5]. Мутуалистические симбиозы с полезными для растений почвенными микроорганизмами предоставляют растениям дополнительные возможности для их выживания в различных условиях, а микросимбионтам - продукты фотосинтеза и экологическую нишу [3, 6-8].

К сожалению, в большинстве работ, связанных с адаптацией растений, полученных методом in vitro [9-11] к условиям внешней среды, крайне мало внимания уделяется их генно-метаболической интеграции с микроорганизмами для снижения стресса, повышения иммунитета, а также улучшения ростовых процессов. Таким образом становится очевидным важность поиска и подбора 


\section{МОЛОДЕЖНАЯ НАУКА КАК ФАКТОР И РЕСУРС ИННОВАЦИОННОГО РАЗВИТИЯ}

штаммов микроорганизмов способных вступать в симбиотические взаимоотношения с растениями и при этом повышать их жизнеспособность и конкурентоспособность в условиях ех vitro.

Целью настоящего исследования было проведение оценки влияния некоторых штаммов бактерий Pseudomonas Migula на морфометрические показатели растений Syringa vulgaris L. сорта Примроуз, полученных методом in vitro на этапе адаптации к условиям внешней среды.

Для адаптации к нестерильным условиям укорененные in vitro pacтения сирени высаживались в рассадные кассеты с объемом ячейки 50 мл, заполненные минерализованным торфяным субстратом. После высадки растений, субстрат в рассадных кассетах проливали до полного смачивания растворами, содержащими штаммы бактерий - Pseudomonas chlororaphis 16H, Pseudomonas protegens P4-2 и Pseudomonas putida Р82 в разведениях с водой 1:5 и 1:10. В качестве контроля выступали растения, обработанные после высадки в субстрат водой без добавок. Кассеты с высаженными растениями размещались в парниках. В течении 30 дней влажность в парниках плавно снижали. После завершения процесса адаптации проводили оценку некоторых морфометрических параметров растений.

Полученные данные по влиянию различных штаммов Pseudomonas Migula на морфометрические показатели надземной и подземной частей растений Syringa vulgaris L. сорта Примроуз представлены на рисунках 1, 2.

Растения, полученные методом in vitro, до адаптации имели одинаковое количество междоузлий, но отличались по средним значениям высоты растений. После завершения адаптации растения, обработанные штаммами Pseudomonas Migula, одинаково увеличили количество междоузлий, что и контрольные растения, за исключением растений субстрат которых был обработан Pseudomonas chlororaphis 16Н. Поскольку средняя высота растений в группах отличалась, то для оценки полученных данных использовали оценку темпа прироста. При этом достоверное влияние на увеличение длинны побега было отмечено только для штамма Pseudomonas protegens P4-2 в разведении $1: 10$ и 1:5, что составило порядка 76,6\% и 77,5\% по сравнению с контролем (62,2\% прироста). 


\section{МОЛОДЕЖНАЯ НАУКА КАК ФАКТОР И РЕСУРС ИННОВАЦИОННОГО РАЗВИТИЯ}

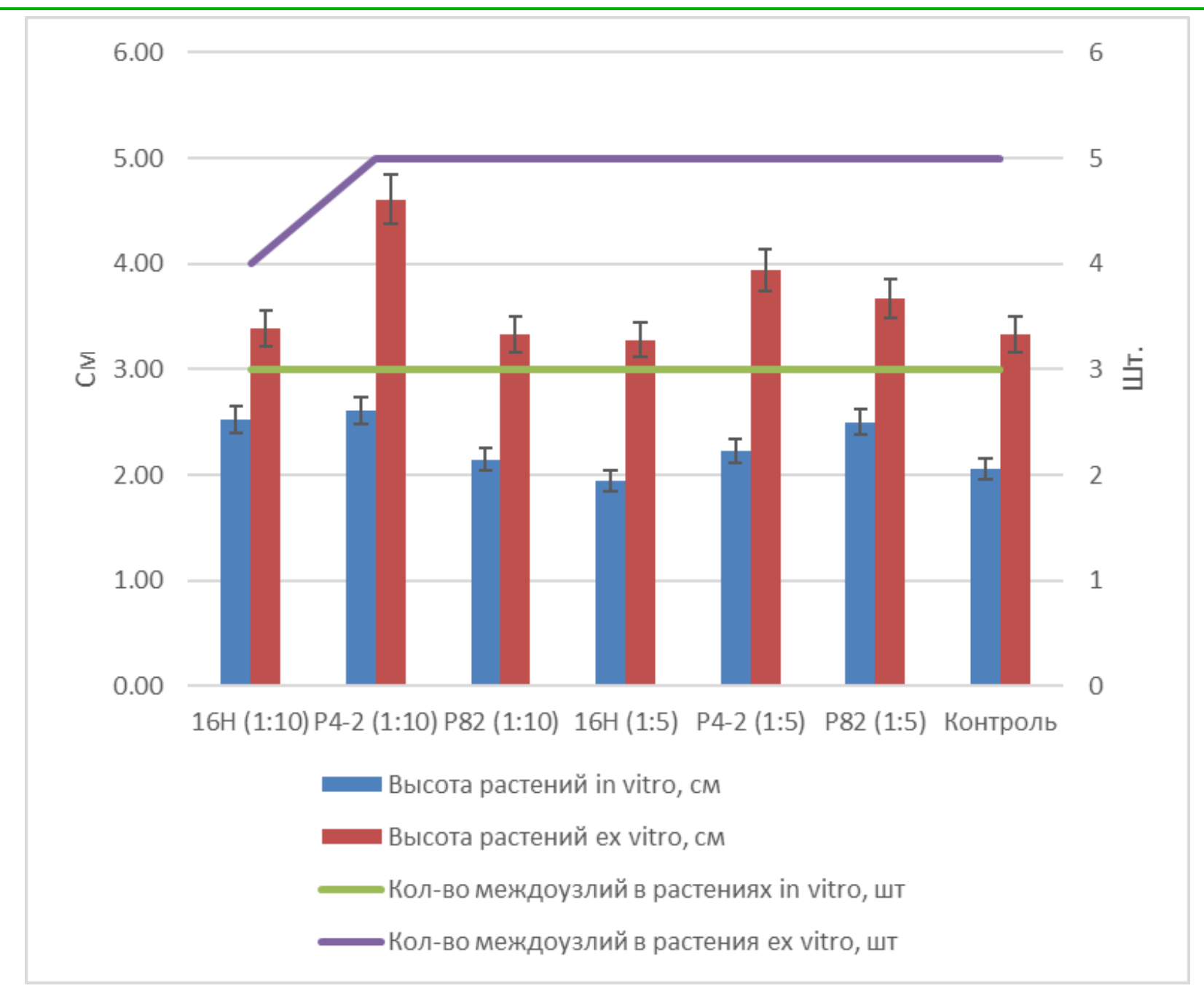

Рис. 1. Влияние обработки штаммами Pseudomonas Migula на морфометрические показатели надземной части растений Syringa vulgaris L. сорта Примроуз

На рисунке 2 видно, что обработка субстрата штаммом Pseudomonas chlororaphis $16 \mathrm{H}$ в разведении 1:10 и 1:5, а также Pseudomonas protegens $\mathrm{P} 4-2$ в разведении 1:5 не привела к увеличению количества корней по сравнению с контролем. Несмотря на достоверность увеличения длины корней при обработке субстрата Pseudomonas protegens P4-2 в разведении 1:5, общая площадь корневой системы была достоверна выше только при использовании штамма Pseudomonas putida P82 в разведении 1:5 (35,3\% прироста по сравнению с контролем) и 1:10 (59,2\% по сравнению с контролем). 


\section{МОЛОДЕЖНАЯ НАУКА КАК ФАКТОР И РЕСУРС ИННОВАЦИОННОГО РАЗВИТИЯ}

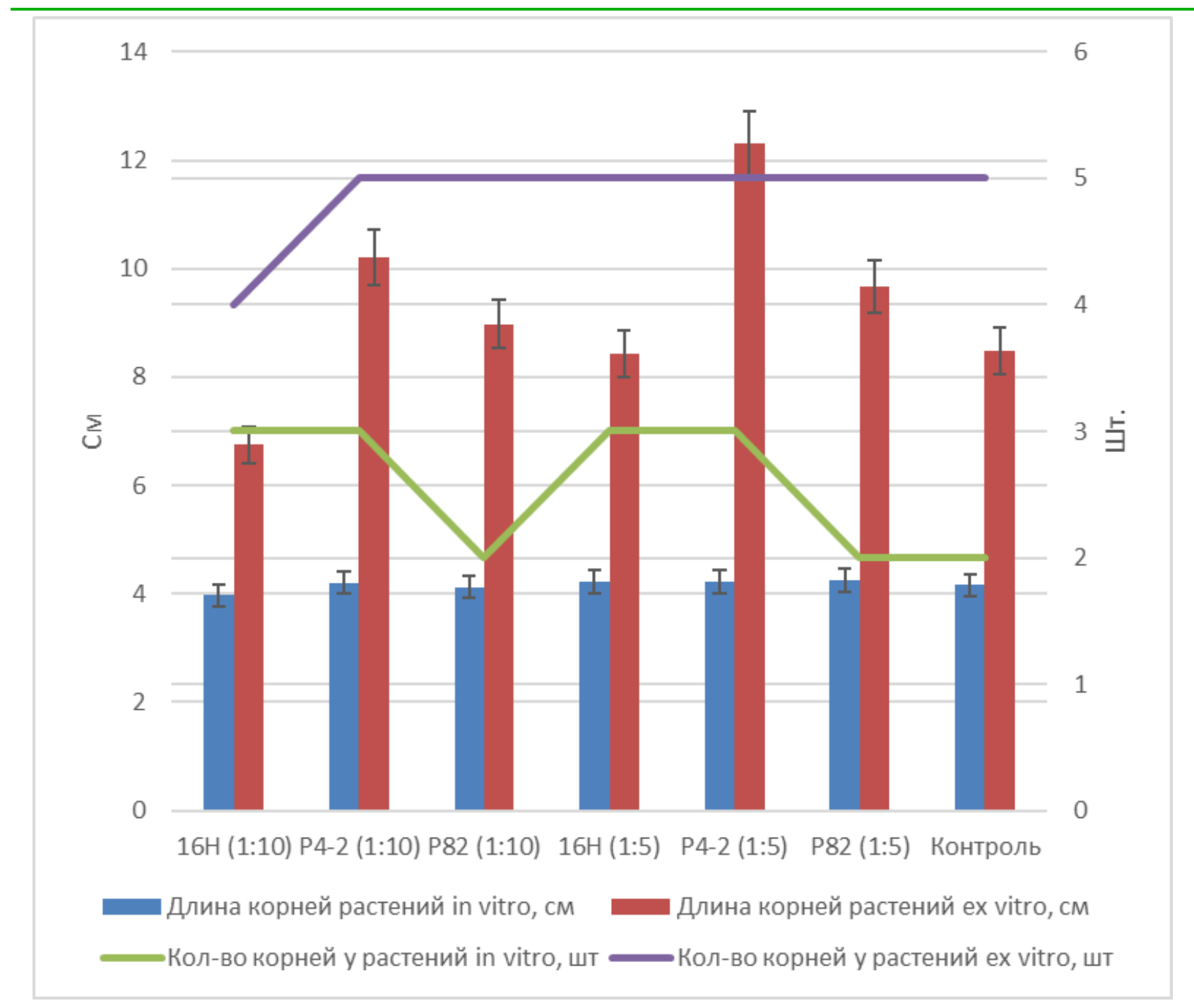

\section{Рис. 2. Влияние обработки штаммами Pseudomonas Migula на}

морфометрические показатели корневой системы растений Syringa vulgaris

\section{L. сорта Примроуз}

Проведенное исследование позволило установить, что на этапе адаптации растений Syringa vulgaris L. сорта Примроуз, полученных методом in vitro к нестерильным условиям, обработка субстрата штаммом бактерий Pseudomonas protegens $\mathrm{P} 4-2$ в разведении 1:5 достоверно увеличивает длину корней и высоту растений. В качестве штамма, способствующего лучшему корнеобразованию (увеличению количества и длины корней), можно рекомендовать обработку субстрата суспензией, содержащей Pseudomonas putida P82 в разведении 1:10.

Таким образом, обработка субстратов суспензиями штаммов Pseudomonas Migula в определенных разведениях и комбинациях может направленно 
стимулировать развитие различных органов растений Syringa vulgaris L. сорта Примроуз на этапе адаптации растений in vitro к условиям внешней среды.

Исследование выполнено при поддержке гранта Министерства науки и высшего образования РФ в рамках государственного задания по теме «Разработка и внедрение в практику комплексных физико-химических методов оценки состояния растений для решения задач направленного формирования устойчивых культурфитоценозов различного функционального назначения в условиях промышленных и аграрных предприятий» для создания лаборатории физико-химических методов исследования растений.

\section{Список литературы:}

1. Геринг Х. Преодоление витрификации и улучшение акклиматизации растений при клональном микроразмножении // Биология культивируемых клеток и биотехнология растений. - М.: Наука, 1991. - С. 197-200.

2. Игнатов В. В. (ред.), 2005. Молекулярные основы взаимоотношений ассоциативных микроорганизмов с растениями. М.: Наука, 262 с.

3. Bakker P. A. H. M., Raaijmakers J. M., Bloemberg G. et al. (eds.), 2007. New perspectives and approaches in plant growth-promoting rhizobacteria research (Reprinted from Eropean Journal of Plant Pathology, 119:2, 2007). Dordrecht: Springer. $126 \mathrm{p}$.

4. Compant S., Duffy B., Nowak J., Clément C., Barka E. A., 2005. Use of plant growth-promoting bacteria for biocontrol of plant diseases: principles, mechanisms of action, and future prospects // Appl. Environ. Microbiol. Vol.71. P. 4951-4959.

5. Schulz B., Boyle S., Sieber T. (eds.), 2006. Microbial root endophytes. Dordrecht: Springer. 367 p.

6. Smith S. E., Read D. J., 2008. Mycorrhizal symbiosis, 3nd ed. Maryland Heights, USA: Elsevier, Academic Press. 800 p.

7. Koltai H., Kapulnik Y. (eds.), 2010. Arbuscular mycorrhizas: physiology and function. Dordrecht: Springer. $623 \mathrm{p}$.

8. Dilworth M. J., James E. K., Sprent J. I., Newton W. E. (eds.), 2008. Nitrogen-fixing leguminous symbioses. Dordrecht: Springer. 404 p.

9. Шакина Т.Н. Опыт адаптации растений-регенерантов некоторых сортов сирени обыкновенной в УНЦ «Ботанический сад» СГУ // В сборнике: 
Syringa L.: коллекции, выращивание, использование. Сборник научных статей. Санкт-Петербург, 2020. С. 179-182.

10. Спиридович Е., Брель Н., Зубарев А., Гончарова Л., Решетников В. Сирень из пробирки // Наука и инновации. 2019. № 6 (196). С. 32-37.

11. Крючкова В.А., Исачкин А.В., Шишканова К.Э. Влияние числа пассажей и продолжительности укоренения in vitro на адаптацию микрорастений сирени обыкновенной (Syringa vulgaris L.) // В сборнике: Биотехнология. Взгляд в будущее. Материалы III Международной научной Интернет-конференции: в 2 томах. Составитель Д.Н. Синяев. 2014. С. 130-134.

12. E. Refouvelet, S. Le Nours, C. Tallon, F. Daguin A new method for in vitro propagation of lilac (Syringa vulgaris L.): Regrowth and storage conditions for axillary buds encapsulated in alginate beads, development of a pre-acclimatisation stage May 1998 Scientia Horticulturae 74(3):233-241 DOI:10.1016/S03044238(98)00088-0.

() Л.А. Тохтарь, М.Ю. Третьяков, Н.Н. Ткаченко, Н.В. Жиляева, 2021 